\title{
Progress in organic reactions catalyzed by bimetallic nanomaterials
}

\author{
Shuangfei Cai a,b, Dingsheng Wang a , Zhiqiang Niu a, Yadong Li a,* \\ a Department of Chemistry, Tsinghua University, Beijing 100084, China \\ ${ }^{\mathrm{b}}$ National Center for Nanoscience and Technology, Beijing 100190, China
}

\section{A R T I C L E I N F O}

\section{Article history:}

Received 20 July 2013

Accepted 2 September 2013

Published 20 November 2013

Keywords:

Bimetallic nanomaterial

Catalyst

Organic reaction

Heterogeneous catalysis

\begin{abstract}
A B S T R A C T
Nanocatalysis, which is also known as semi-heterogeneous catalysis, sits at the boundary between homogeneous catalysis and heterogeneous catalysis and has been the subject of increasing interest during the course of the last few years. Significant progress has recently been made towards the catalytic applications of bimetallic nanomaterials, which show high levels of activity, selectivity and recyclability. This review provides a summary of bimetallic nanomaterial-catalyzed organic transformations, including selective oxidation, hydrogenation, and coupling reactions, as well as dechlorination, amidation, reductive amination, and hydrogenolysis reactions, and the asymmetric 1,4-addition reactions of arylboronic acids to enones. The complex organic molecules using bimetallic nanocatalysis would be anticipated soon. There is significant scope for bimetallic nanocatalysts to be further developed in terms of our general understanding of their fundamental properties and practical applications. Future development may benefit from the rational design and controllable synthesis of bimetallic nanomaterials, as well as a deeper understanding of their reaction mechanisms and further progress towards the development of sophisticated computational studies involving catalysis, which would require interdisciplinary collaborations.
\end{abstract}

(C) 2013, Dalian Institute of Chemical Physics, Chinese Academy of Sciences. Published by Elsevier B.V. All rights reserved.

\section{Introduction}

The field of heterogeneous catalysis, with particular emphasis on catalysis involving bimetallic nanomaterials (BNMs) that contain two different materials in the same nanoparticle, has seen many advances over the past few years. For example, significant progress has been made with regard to the preparation and characterization of a variety of different BNMs with welldefined size, shape, and composition properties [1-5]. Furthermore, to allow for the development of a deeper understanding of the origins of their novel catalytic properties, extensive mechanistic studies have been directed towards heterogeneous catalysis, as summarized in several reviews [6-12].

BNMs not only combine the properties of their individual constituents but also show unique properties that are superior to those of the ordinary materials, and therefore provide an opportunity for the development of novel catalysts with enhanced activity, selectivity, and stability. The term "bimetallic clusters" was introduced by Sinfelt [13] in the early 1980s. The synergistic catalytic effects of BNMs have been attributed to the "ligand" and "ensemble" effects of bimetallic clusters [14,15]. The ligand effect results from changes in the properties of the cluster surface that are caused by the exchange of electrons between the core metal and surface metal particles, whereas the ensemble effect is derived from the independent activation of substrates on each metal atom on the cluster surface. In this review, we will focus on recent progress in the field of BNMcatalyzed organic reactions.

\footnotetext{
*Corresponding author. Tel: +86-10-62772350; Fax: +86-10-62788765; E-mail: ydli@mail.tsinghua.edu.cn

This work was supported by the State Key Project of Fundamental Research for Nanoscience and Nanotechnology (2011CB932401, 2011CBA00500, 2012CB224802) and the National Natural Science Foundation of China $(21221062,21171105,21322107,21131004)$. 


\section{Organic reactions catalyzed by bimetallic nanomaterials}

\subsection{Selective oxidations}

Oxidation reactions, especially the catalytic oxidations of hydrocarbons using molecular oxygen as an oxidant, are of considerable industrial importance $[16,17]$, and research towards improving the efficiency and selectivity of oxidation reactions for valuable commercial products remains a challenge. For this reason, the development of effective catalysts that can activate oxygen is highly desirable [18].

Following on from the first Au cluster-catalyzed oxidation reaction reported by Haruta et al. [19], there has been significant interest in Au catalysts from both the academic and industrial communities. In this respect, Au nanomaterials are known to exhibit outstanding catalytic activity for the aerobic oxidation of alcohols [20-23].

A variety of different $\mathrm{Au}-\mathrm{M}(\mathrm{M}=\mathrm{Cu}, \mathrm{Pd}, \mathrm{Pt}, \mathrm{Ag}) \mathrm{BNMs}$ have recently been prepared for the selective oxidation of alcohols, where they provided significant improvements in the catalytic efficiency of this transformation. For example, $\mathrm{Au}-\mathrm{Cu} / \mathrm{SiO}_{2}$ prepared using the codeposition-precipitation method was used in the gas-phase oxidation of benzyl alcohol to benzaldehyde [24]. When $\mathrm{Au}$ and $\mathrm{Cu}$ were used separately to catalyze this reaction, the yields of benzaldehyde were $74 \%$ and $40 \%$, respectively. In contrast, the combination of $\mathrm{Au}$ and $\mathrm{Cu}$ resulted in $>98 \%$ yield under the optimized catalyst composition conditions, i.e., $\mathrm{Cu}: \mathrm{Au}=1: 4$ (mol $/ \mathrm{mol})$.

In a separate piece of research, Wang et al. [25,26] found that the addition of Ag not only led to a significant enhancement in the rate of the reaction but also led to an increase in the apparent activation energy compared with that of the monometallic Au nanocatalyst. Zhang et al. [27] showed that a $\mathrm{Au}-\mathrm{Cu}$ alloy catalyst supported on silica exhibited better activity and selectivity towards the oxidation of a variety of different alcohols to aldehydes compared with the corresponding $\mathrm{Au}-\mathrm{Ag}$ alloy.

Interestingly, Hirai et al. [28] reported that a supported $\mathrm{Au}-\mathrm{Cu}$ nanoalloy promoted the aerobic oxidation of 2-propanol to acetone under visible light (Scheme 1 ). The surface $\mathrm{Cu}$ atoms were oxidized by $\mathrm{O}_{2}$ during this reaction before being successfully reduced by the plasmon-activated $\mathrm{Au}$ atoms. This catalytic system allowed for activity regeneration via the plasmon activation of $\mathrm{Au}$ atoms by visible light. Importantly, this could contribute to the design of more efficient catalytic systems and may provide a new strategy for the development of green organic transformations using sunlight.

$\mathrm{Au}$-Pd bimetallic catalysts for the oxidation of alcohols have also been studied extensively. For example, the SBA-16-immobilized $\mathrm{Au}-\mathrm{Pd}$ catalyst performed effectively for the selective oxidation of benzylic alcohols to the corresponding aldehydes

$$
\overbrace{5 \mathrm{~mL}}^{\mathrm{OH}} \frac{\text { catalyst }(5 \mathrm{mg}), \mathrm{O}_{2}(1 \mathrm{~atm}), 298 \mathrm{~K}, 12 \mathrm{~h}}{\text { visible light irradiation or dark }}
$$

Scheme 1. The aerobic oxidation of 2-propanol to acetone [28].
[29]. Scott et al. [30] compared the poly(vinylpyrrolidone) (PVP) stabilized Au-Pd core-shell nanomaterials prepared either using a Au nanoparticle as a seed via the sequential reduction of the $\mathrm{Au}$ and $\mathrm{Pd}$ precursors or the coreduction of $\mathrm{Au}$ and Pd precursors. The sequentially reduced nanoparticles possessed Pd-rich surfaces and displayed better catalytic activity for selective aerobic oxidation of crotyl alcohol to crotonaldehyde at room temperature.

Kobayashi et al. [31] reported the preparation of a $\mathrm{Au}-\mathrm{Pt}$ catalyst using a cross-linked polystyrene derivative as support, which showed good activity for the selective oxidation of secondary and cyclic alcohols to the corresponding ketones, with yields in the range of $67 \%-99 \%$. Prati et al. [32,33] compared the catalytic activities of Au-Pd and Au-Pt BNMs with similar particle size distribution and microstructure characteristics for the oxidation of several alcohols, including cinnamyl alcohol, benzyl alcohol, and 1-octanol, to the corresponding aldehydes. These catalysts were prepared by dipping premade $\mathrm{Au} / \mathrm{C}$ into a solution of the Pd or Pt precursor containing polyvinylalcohol. Better catalytic performance was achieved in water with $0.73 \%$ $\mathrm{Au}-0.27 \% \mathrm{Pd} / \mathrm{C}$. Subsequent characterization of these materials suggested that these two catalysts were single-phase catalysts that only presented the alloyed phases of a single composition.

Notably, the oxidation of primary alkyl alcohols remains a challenge because these catalysts are usually inactive in this reaction. In 2006, Hutchings et al. [34] demonstrated that a $\mathrm{TiO}_{2}$-supported $\mathrm{Au}-\mathrm{Pd}$ nanocatalyst could be used to give very high turnover frequencies (TOF, up to $270000 \mathrm{~h}^{-1}$ ) for the oxidation of alcohols, including primary alkyl alcohols. The addition of $\mathrm{Au}$ to Pd nanocrystals to these reactions led to improved selectivity for the formation of aldehydes. Using scanning transmission electron microscopy (STEM) and X-ray photoelectron spectroscopy (XPS), the Au-Pd nanocrystals were shown to consist of a Au-rich core with a Pd-rich shell. These results indicated that the Au would electronically influence the catalytic properties of the Pd.

Another elegant example of the selective oxidation of primary alcohols was reported by Kobayashi et al. [35], who used a carbon black-stabilized polymer-incarcerated (PI/CB) Au-M $(\mathrm{M}=\mathrm{Pt}, \mathrm{Pd})$ catalysts. Importantly, it was possible to change the reaction pathway dramatically under Au catalysis by combining the Au with a second metal (Scheme 2). The reactivity and the selectivity of these reactions were found to be strongly dependent on the combination of metals and solvent systems, in that the use of the Au-Pt catalyst in benzotrifluoride provided aldehydes and ketones, whereas the use of the Au-Pd catalyst in methanol gave esters. This was attributed to the differences in the structure of the bimetallic clusters. STEM and energy dispersive spectroscopy analyses suggested the formation of $\mathrm{Au}-\mathrm{Pt}$ clusters containing a 1:1 ratio of $\mathrm{Au}$ to $\mathrm{Pt}$ in one case,

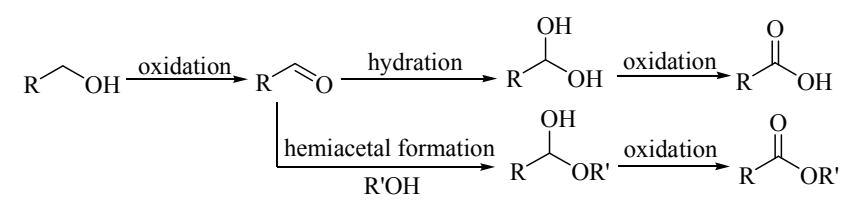

Scheme 2. Two possible reaction pathways for the oxidation of alcohols [35]. 


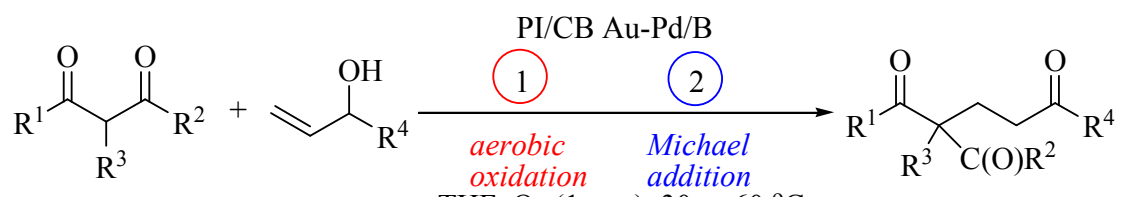

THF, $\mathrm{O}_{2}(1 \mathrm{~atm}), 30$ or $60{ }^{\circ} \mathrm{C}$

Scheme 3. Polymer-incarcerated Au-Pd nanoclusters with boron on carbon: A mild and efficient catalyst for the sequential aerobic oxidation-Michael addition of 1,3-dicarbonyl compounds to allylic alcohols [36].

and the formation of Au-Pd clusters containing a 4:1-3:1 ratio of $\mathrm{Au}$ to $\mathrm{Pd}$ in the other case. Further research efforts are needed to clarify the role of carbon in these reactions, as well as the effect of the bimetallic clusters, and the reaction mechanisms.

As a representative example of achieving the synthesis of complex molecules using bimetallic nanocatalysis, Kobayashi et al. [36] reported the use of a polymer-incarcerated Au-Pd nanocluster and boron as a catalytic system for the sequential oxidation-Michael addition reaction of 1,3-dicarbonyl compounds to allylic alcohols (Scheme 3). Under anhydrous and relatively neutral conditions, the $\mathrm{Au}-\mathrm{Pd}$ nanoclusters were found to be particularly effective for the aerobic oxidation of allylic alcohols. The immobilized tetravalent boron catalyst for the Michael reaction was obtained from the reaction of an excess of the reducing agent (sodium borohydride) with the polymer backbone. The target products were obtained in good to excellent yields with broad substrate scope.

Despite the crucial importance of methods for the selective oxidation of primary $\mathrm{C}-\mathrm{H}$ bonds with oxygen, to date, heterogeneous catalysts have either shown low activity and/or selectivity or required activated oxygen donors. Recent developments in this area by Hutchings et al. [37] have demonstrated that $\mathrm{Au}-\mathrm{Pd} / \mathrm{C}$ and $\mathrm{Au}-\mathrm{Pd} / \mathrm{TiO}_{2}$ catalysts can be used successfully for the oxidation of the primary $\mathrm{C}-\mathrm{H}$ bonds in toluene and related molecules to give the corresponding benzyl benzoate compounds with high selectivity under mild solvent-free conditions. The difference in the catalytic activity of the Au-Pd nanoparticles on the different supports was attributed to differences in the wetting behavior of the supports and the availability of exposed corner/edge sites. Using tert-butyl hydroperoxide as the principal oxygen donor, surface-bound oxygen-centered radicals were found to play a role in activating toluene, as observed in the $\mathrm{Au}-\mathrm{Pd} / \mathrm{TiO}_{2}$-catalyzed selective oxidation of toluene reported by Hutchings et al. [38]. Although the contribution of these surface-bound radicals to the overall oxidation reaction has not yet been fully delineated, the observation of this new pathway will undoubtedly aid and inform future catalyst design.

\subsection{Selective hydrogenations}

Based on the requirements for sustainable development, as well as the desirability of using molecular hydrogen as a chemical reagent, it is of paramount importance that the chemistry community can rise to these challenges and develop highly active and selective catalysts for the hydrogenation of organic molecules, including $\alpha, \beta$-unsaturated carbonyl compounds, simple alkenes and alkynes, as well as substituted nitroarenes (Scheme 4).

Metal nanoparticles containing elements in groups VIII-X of the periodic table, such as $\mathrm{Ni}, \mathrm{Pd}, \mathrm{Ru}$, and Pt [39-42], have been studied extensively as selective catalysts for a variety of different hydrogenation reactions. To study the structure-activity relationships of BNMs, several BNMs with tunable sizes and shapes were rationally designed and synthesized in a controlled manner. In a typical example reported by Tsang et al. [43], Pt-Co nanoalloy was prepared for the selective hydrogenation of $\alpha, \beta$-unsaturated aldehydes (cinnamaldehyde and citral) to $\alpha, \beta$-unsaturated alcohols. Pt nanocrystals of specific tailored sizes were decorated with Co atoms in a controlled manner in colloid solution. Using Co-decorated Pt nanocrystals with a critical size range, they successfully achieved the hydrogenation of terminal $\mathrm{C}=\mathrm{O}$ groups with high activity, whereas the undesirable hydrogenation of the $\mathrm{C}=\mathrm{C}$ group was totally suppressed as a result of the blockage of the unselective low coordination sites and the optimization of the electronic influences of the Pt nanoparticles of the appropriate size resulting from the Co decoration process.

Chen et al. [44] showed that $\mathrm{SiO}_{2}$-supported $\mathrm{M}-\mathrm{Pt}(\mathrm{M}=\mathrm{Co}$, $\mathrm{Cu}$ ) bimetallic catalysts exhibited much higher activity towards the hydrogenation of cinnamaldehyde than the corresponding monometallic catalysts, with Co-Pt affording much higher selectivity towards $\mathrm{C}=\mathrm{O}$ bond hydrogenation than $\mathrm{Cu}-\mathrm{Pt}$.

Various monometallic catalytic systems have been reported for the selective hydrogenation of arenes and functionalized nitroarenes, as reviewed by Claver et al. [45] and Blaser et al. [46], respectively. Tan et al. [47] reported a series of Pd-Ag bimetallic colloids that were synthesized in $\mathrm{CO}_{2}$-expanded hexane from the corresponding isostearate salts, $\mathrm{Pd}\left(\mathrm{C}_{18} \mathrm{H}_{35} \mathrm{O}_{2}\right)_{2}$

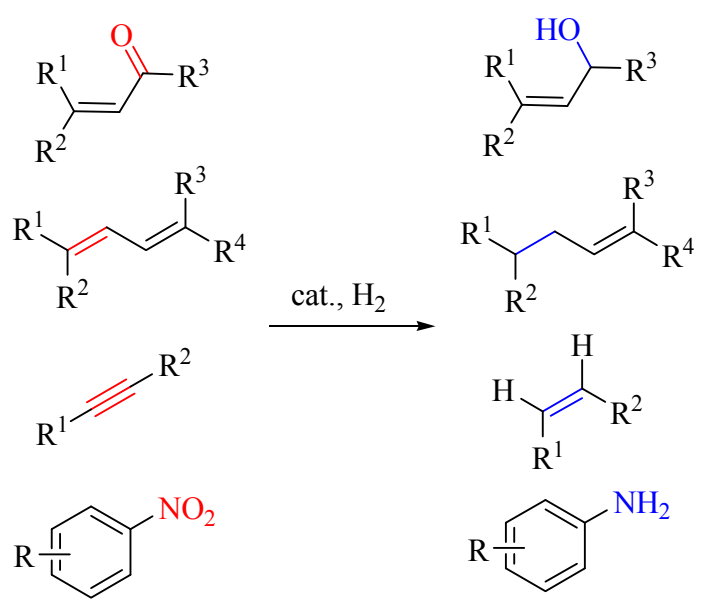

Scheme 4. Several important selective hydrogenation reactions. 


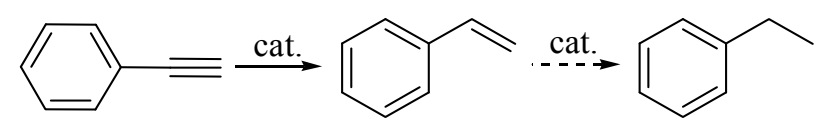

Scheme 5. Partial hydrogenation of phenylacetylene [47].

and $\mathrm{Ag}\left(\mathrm{C}_{18} \mathrm{H}_{35} \mathrm{O}_{2}\right)_{2}$. Further research revealed that the addition of $\mathrm{CO}_{2}$ inhibited the growth of the nanoparticles and made their particle sizes smaller. High activity and selectivity towards styrene were achieved when $\mathrm{Pd}_{25} \mathrm{Ag}_{75}$ was used in a $20 \% \mathrm{CO}_{2}$ system (Scheme 5).

In addition to Pd-Ag, bimetallic nanocatalysts containing noble and non-noble metals have been reported and represent a novel type of nanocatalyst. To investigate the structure-activity relationships of BNMs, we synthesized water-soluble Pt, $\mathrm{Pt}_{x} \mathrm{Ni}_{1-x}(0<x<1)$, and Ni nanocatalysts with uniformly controlled shapes and compositions, and found that their catalytic activities in the three model reactions (Scheme 6) were positively related to the percentage of exposed $\{111\}$ facets [48]. Furthermore, the bimetallic nanocatalysts were found to be more active than their monometallic counterparts, suggesting the occurrence of a synergistic effect between the two metals. Using PVP as a capping agent prevented the catalyst from post-synthesis treatment without compromising the catalyst's solubility, activity, and recyclability. The general and facile synthesis of these nanocrystals coupled with their high activity and stability, warrant further studies of the oxidation mechanism and potential application of these nanocrystals.

We also fabricated Rh-Ni bimetallic nanocrystals using our "noble metal-induced reduction" strategy [4,49], and the resulting catalysts displayed high activity towards the hydrogenation of a wide range of substrates at room temperature, including olefins, nitroarenes, and arenes [50].

Chen et al. [51] evaluated $\gamma-\mathrm{Al}_{2} \mathrm{O}_{3}$-supported Pt-Ni catalysts for the hydrogenation of benzene and 1,3-butadiene. The results revealed that catalysts with a smaller $\mathrm{Pt} / \mathrm{Ni}$ ratio exhibited higher levels of activity, and that the catalysts synthesized using the co-impregnation method had higher activity than the sequentially impregnated catalysts.

$\mathrm{Ni}-\mathrm{Zn}$ was developed as a promising nanocatalyst for the selective hydrogenation of acetylene by Nørskov et al. [52] based on density functional theory calculations and experimental studies. It is noteworthy that this particular catalyst is less expensive and more readily available than the Ag-modified Pd hydrogenation catalyst, which is currently used industrially for the removal of trace acetylene from ethylene. Different

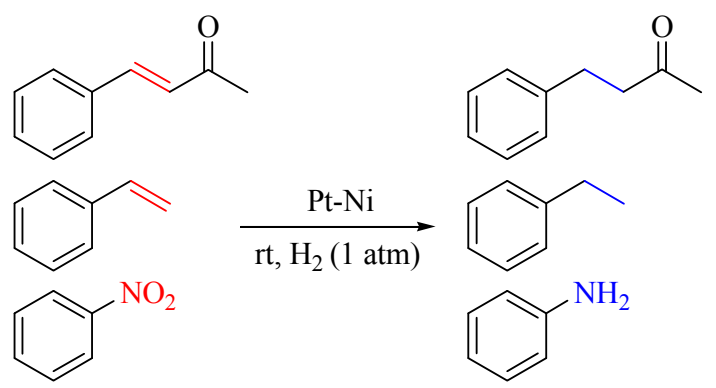

Scheme 6. Hydrogenation of benzalacetone, styrene, and nitrobenzene catalyzed by Pt-Ni nanoalloy [48].
Ni-Zn catalysts have been compared with the well-established Pd-Ag system, and the results revealed that the selectivity of the Ni-Zn catalyst increased substantially as the amount of $\mathrm{Zn}$ was increased, and the Ni-Zn catalyst containing 75\% Zn exhibited higher selectivity than the best Pd-Ag catalyst containing $75 \%$ Ag. Furthermore, the Ni-Zn catalysts appeared to be more stable than those for $\mathrm{Cu}$ [53-55]. Another nanocatalyst is Co-Pd, which can be synthesized in two different ways using the polyol methods described by Bäumer et al. [56] for the hydrogenation of acetylene. The Co-Pd stabilized by PVP during the synthesis showed higher ethylene selectivity than those prepared directly on different supports, including active carbon, $\mathrm{MgO}$ and $\gamma-\mathrm{Al}_{2} \mathrm{O}_{3}$.

In view of the low cost, low toxicity and environmentally benign properties of Fe, Yamamoto et al. [57] developed a bimetallic Rh-Fe catalyst for the hydrogenation of olefins and nitroarenes under mild conditions. The catalyst showed improved catalytic activity towards these hydrogenation reactions compared with previously reported hydrogenation reactions using $\mathrm{Rh}$ nanocatalysts in dendrimer cages, and provided new critical experimental parameters for the design and optimization of durable nanocatalysts.

Based on the synthesis of the Rh-Ni alloy reported earlier [50], we evaluated the catalytic performance of a series of $\mathrm{Rh}_{x} \mathrm{Ni}_{y}(x, y=1,2,3)$ nanoparticles in the selective hydrogenation of nitroarenes [58]. The unsupported $\mathrm{Rh}_{3} \mathrm{Ni}_{1}$ nanoparticles were found to be highly active and incredibly selective for the hydrogenation of a range of substituted nitroarenes under ambient conditions; underscoring the remarkable synergistic effect of the two metals. These unsupported $\mathrm{Rh}_{3} \mathrm{Ni}_{1}$ nanoparticles were also found to be recyclable. Overall, this work effectively showcased the value of bimetallic nanocatalysts in the development for sustainable chemistry.

Using nontoxic and renewable degraded pueraria starch as a reducing agent and a capping agent, as well as a matrix, Li et al. [59] developed the well-stabilized $\mathrm{Au}-\mathrm{Ag}$ nanocatalyst for the reduction of 4-nitrophenol by $\mathrm{NaBH}_{4}$ and found this catalyst to be more effective for this reduction than the corresponding Au or Ag nanoparticles.

$\mathrm{Xu}$ et al. [60] reported the preparation of $\mathrm{Au}_{\text {core }}-\mathrm{Ag}_{\text {shell }}$ nanoparticles immobilized on a metal-organic framework using a sequential deposition-reduction method and found that it was possible to tune the composition of the resulting Au-Ag nanoparticles by making changes to the $\mathrm{Au} / \mathrm{Ag}$ ratio. They also found that the structure of the Au-Ag nanoparticles could be changed by reversing the $\mathrm{Au} / \mathrm{Ag}$ deposition sequence, and that a post-treatment process could be used to convert the $\mathrm{Au}_{\text {core- }}$ $\mathrm{Ag}_{\text {shell }}$ nanoparticles to a $\mathrm{Au}-\mathrm{Ag}$ alloy. The $\mathrm{Au}$ core- $\mathrm{Ag}_{\text {shell }}$ nanoparticles showed a strong bimetallic synergistic effect towards the reduction of 4-nitrophenol by $\mathrm{NaBH}_{4}$ in water and exhibited a much higher activity than the corresponding alloy and monometallic nanoparticles.

Keane et al. [61] prepared bimetallic $\mathrm{Pd}-\mathrm{Au} / \mathrm{Al}_{2} \mathrm{O}_{3}$ nanoparticles using the deposition-precipitation (DP) and impregnation (IMP) methods with different molar ratios of $\mathrm{Au} / \mathrm{Pd}(8,20$, and 88). The inclusion of $\mathrm{Pd}$ (at $\mathrm{Au} / \mathrm{Pd}=20$, IMP and DP) resulted in a 3-fold increase in the activity whilst retaining exclusivity 
towards 4-chloroaniline.

Most recently, Corbos et al. [62] showed that the Pd-Au BNMs prepared in a one-spot synthesis using a colloidal approach displayed high activity in the selective hydrogenation of 2-chloronitrobenzene. They also found that the structure of the $\mathrm{Pd}-\mathrm{Au}$ had a significant influence on the outcome of the reaction, with a Pd-rich surface providing superior selectivity and reaction rates.

Liu et al. [63] reported the preparation of a Pt-Ru catalyst by immobilizing pre-made Pt-Ru nanoparticles on $\mathrm{SnO}_{2}$. They also found that the resulting catalyst was more active and selective for the hydrogenation of 2-chloronitrobenzene than the corresponding $\mathrm{SnO}_{2}$-supported Pt-Ru catalyst prepared by the classical impregnation method, as a result of the much smaller size and narrower particle size distribution of the Pt-Ru nanoparticles in the former sample.

Qiu et al. [64] synthesized a series of three-dimensional flower-like $\mathrm{Co}-\mathrm{Ni} / \mathrm{C}$ catalysts for the selective hydrogenation of 2-chloronitrobenzene to 2-chloroaniline. The catalysts, which consisted of interlaced carbon flakes with highly dispersed metal nanoparticles, were prepared by a facile hydrothermal/solvothermal process followed by a period of heat treatment in a stream of $\mathrm{N}_{2}$. The conversion of 2-chloronitrobenzene over the $\mathrm{Co}-\mathrm{Ni} / \mathrm{C}$ catalysts was increased by up to $200 \%$ compared with the Co/C catalyst. Hydrogen temperature-programmed desorption results showed that new active sites had formed on the $\mathrm{Co}_{00} \mathrm{Ni}_{50} / \mathrm{C}$ catalyst, as a consequence of the formation of a Co-Ni alloy, which resulting in the improved activity of the $\mathrm{Co}_{50} \mathrm{Ni}_{50} / \mathrm{C}$ catalyst.

In addition, Müslehiddinoğlu et al. [65] developed a $\mathrm{Pd}-\mathrm{Cu} / \mathrm{C}$ catalyst as an alternative to Raney Ni for the highly diastereoselective hydrogenation of imines prepared from prochiral ketones and $\alpha$-phenylethylamines (Scheme 7). These results revealed that chiral amines could be obtained with a diastereomeric excess (de) up to $94 \%$ using $\mathrm{Pd}-\mathrm{Cu} / \mathrm{C}$, whereas conventional $\mathrm{Pd} / \mathrm{C}$ catalysts only afforded a de of $72 \%$. Further investigation revealed that a $\mathrm{Pd}: \mathrm{Cu}$ ratio of $4: 1$ was required for a robust process. Compared with Raney $\mathrm{Ni}$, the key advantages of this bimetallic $\mathrm{Pd}-\mathrm{Cu} / \mathrm{C}$ system include improved safety, no issues with catalyst suspension, and enhanced operational scalability.

\subsection{Coupling reactions}

Pd-catalyzed cross-coupling reactions, such as the Heck, Suzuki, and Sonogashira reactions, have become some of the most important organic transformations in synthetic chemistry for forming $\mathrm{C}-\mathrm{C}$ bonds [66], and the use of $\mathrm{Pd}$ nanoparticles in these coupling reactions has been studied extensively [67-70]. Recent studies on these reactions have focused on enhancing

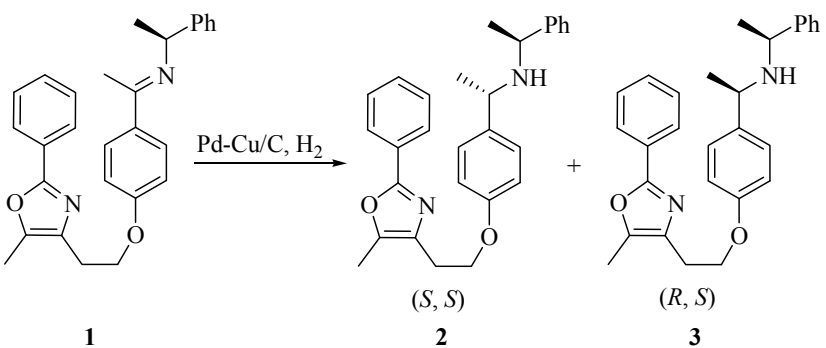

Scheme 7. Catalytic hydrogenation of $\mathbf{1}$ to provide $\mathbf{2}$ by Pd-Cu/C [65].

the activity, selectivity, and stability of the catalysts used as well as elucidating the catalytic reaction mechanisms by designing a variety of novel Pd-based BNMs.

To facilitate the recovery of the catalyst, reduce the usage of $\mathrm{Pd}$, and improve the overall efficiency of these reactions, we prepared a series of magnetically separable "quasi-homogeneous" Pd-Ni nanoalloys with tunable composition properties using a one-pot wet chemical reaction [71]. The resulting catalysts not only showed higher catalytic activity than the equivalent amount of Pd nanoparticles for the Suzuki-Miyaura coupling reaction, but also exhibited excellent recyclability.

To enhance the activity, selectivity, and stability of catalysts for the Suzuki coupling reaction, Chen et al. [72] prepared and evaluated the alloy and the core-shell Au-Pd particles confined in silica nanorattles. The results showed that the conversion and yield for all of the catalysts studied decreased in the order alloy $\mathrm{Au}_{3} \mathrm{Pd}_{1}>\mathrm{Au}_{1} \mathrm{Pd}_{1}>\mathrm{Au}_{1} \mathrm{Pd}_{3}>$ core-shell $\mathrm{Au}-\mathrm{Pd}>\mathrm{Pd}>\mathrm{Au}$. It is noteworthy that the alloy Au-Pd@SiO 2 showed higher selectivity and stability than a commercial $\mathrm{Pd} / \mathrm{C}$ catalyst.

Shaabani et al. [73] reported a highly active catalyst based on Pd-Co alloy nanoparticles supported on polypropylenimine grafted on graphene for the Sonogashira coupling reaction using ultrasound irradiation at room temperature (Scheme 8).

Muraviev et al. [74] developed a highly active, insoluble, and readily separable catalyst based on cross-linked polymers (granulated beads) and core-shell catalytic-magnetic Pd@Co nanoparticles for use in a Suzuki coupling reaction (Scheme 9).

Choi et al. [75] synthesized carbon-supported bimetallic $\mathrm{Pd}-\mathrm{M}(\mathrm{M}=\mathrm{Ag}, \mathrm{Ni}$, and $\mathrm{Cu})$ nanoparticles by $\gamma$-irradiation at room temperature, and the resulting $\mathrm{Pd}-\mathrm{Cu} / \mathrm{C}$ nanoparticles exhibited high catalytic efficiency in the Suzuki- and Heck-type coupling reactions.

Gao et al. [76] reported that montmorillonite supported $\mathrm{Pd}-\mathrm{Cu}$ nanoparticles displayed outstanding catalytic activity towards the Sonogashira coupling reaction. These catalysts were prepared on the basis of the unique metal ion adsorption capacity of montmorillonite and sequential reductive carbonylation via the thermolysis of $N, N$-dimethylformide. Kinetic studies revealed that the water-promoted swelling of the
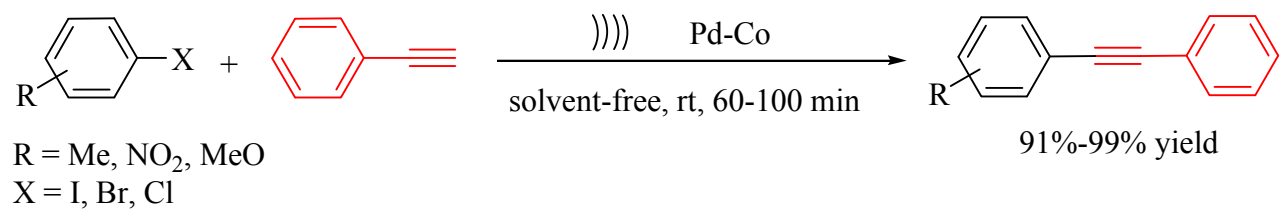

91\%-99\% yield

Scheme 8. Sonogashira coupling with Pd-Co alloy [73]. 


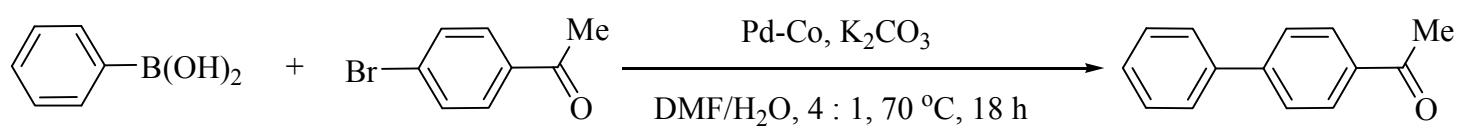

Scheme 9. Suzuki coupling reaction using a Pd@Co catalyst [74].

montmorillonite as well as the $\mathrm{Pd}-\mathrm{Cu}$ bimetallic synergistic effect played a critical role in the high activity of the catalyst.

Despite extensive mechanistic studies on heterogeneous Pd catalysts, the nature of the active species involved Pd catalyzed processes remains a topic of considerable scientific debate [77-79]. Jutand et al. [80] reported the use of $\mathrm{Au}_{\text {core }} \mathrm{Pd}_{\text {shell }}$ nanoparticles to prove the homogeneous origin of the high catalytic efficiency of Pd-based nanoparticles in Suzuki-Miyaura cross-coupling reactions conducted in water at room temperature. The catalytic activity of the $\mathrm{Au}_{\text {core }} \mathrm{Pd}_{\text {shell }}$ nanoparticles was attributed to leaching of the Pd centers or clusters away from the nanoparticles in the presence of the reaction components, as revealed by surface-enhanced Raman spectroscopy, cyclic voltammetry, and inductively coupled plasma-mass spectrometry. They also found that the Pd leaching occurred predominantly as a consequence of the synergistic action of the base and the arylboronic acid and not as a consequence of the oxidative addition by the aryl halide [81]. In addition, it was found that the reactivity of the leached Pd species could be finely tuned by making changes to the number of Pd shells wrapped around the Au core.

Sakurai et al. [82] described an efficient method for the
Ullmann coupling of chloropyridines catalyzed by a PVP-stabilized Au-Pd alloy under ambient conditions (Fig. 1). The corresponding monometallic Au or Pd nanocrystals as well as a mixture of the two metals did not catalyze the reaction. Using ultraviolet-visible spectroscopy and inductively coupled plasma atomic-emission spectroscopy measurements, a significant amount of leached Pd was observed during the reaction, leading to a decrease in the catalytic activity.

To provide additional information pertaining to the structural changes that occur during the Suzuki reaction, we rationally designed Pd and Pd-Au bimetallic alloys (Fig. 2) [83]. Importantly, disordered Pd was found to partly evolve into its well-crystallized counterpart, whereas Pd-Au underwent phase segregation during the reaction. Direct evidence in support of an oxidative-addition-promoted leaching mechanism for the Suzuki reaction was subsequently obtained. This mechanism operates in standalone, carbon, and SBA-supported nanocatalysts, suggesting that true surface-catalysis remains largely unknown in all three of the main types of "heterogeneous" catalysts. Accordingly, efforts aimed at lowering the level of residual Pd could be more fruitful if directed towards considerations other than pursuing true heterogeneous catalysts.

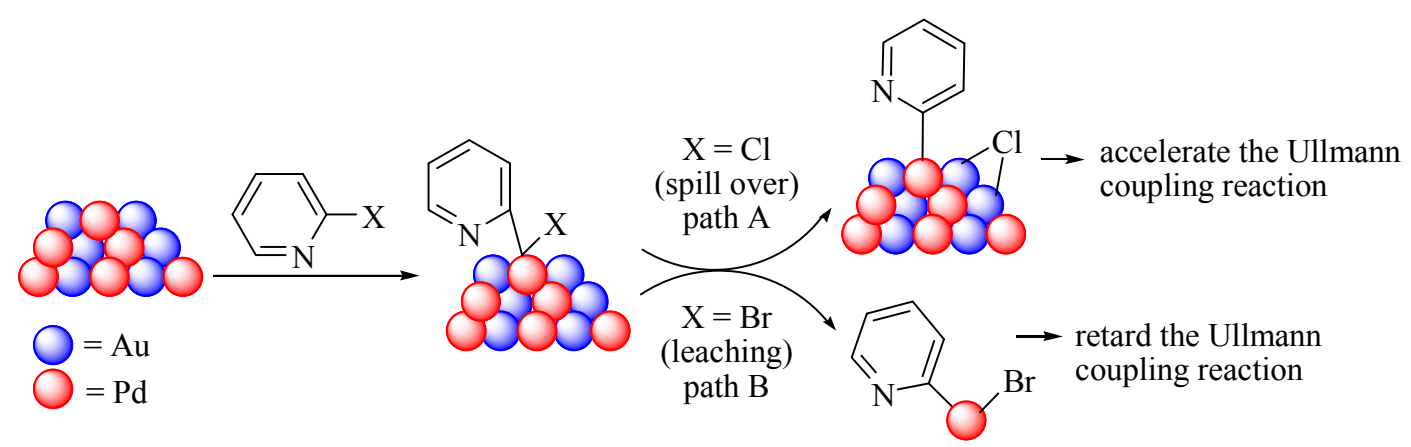

Fig. 1. Mechanistic illustration of the activity of Au-Pd clusters in the Ullmann coupling. Path A represents the activation process, whereas path B represents the deactivation process [82].

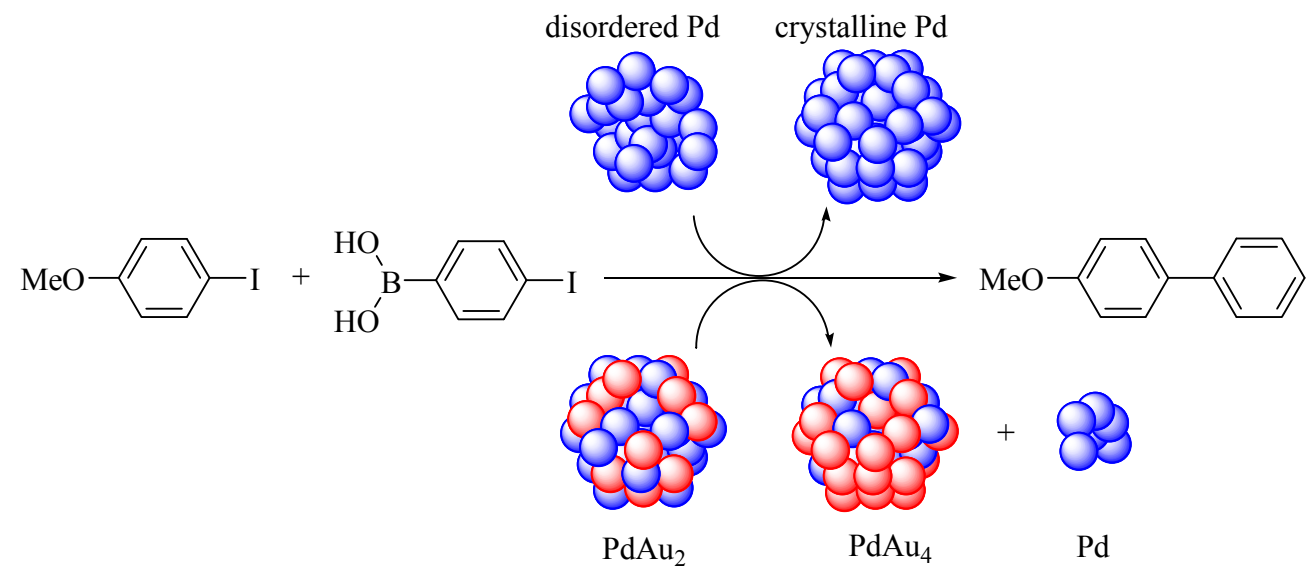

Fig. 2. Schematic illustration of the structural changes taking place to the Pd-based nanocatalysts in the Suzuki-Miyaura reaction [83]. 


\subsection{Other reactions}

\subsubsection{Hydrodechlorination}

In view of environmental hazards associated with chlorinated, toxic organic materials, $\mathrm{Ni}$ [84-87] and several precious metals, including Pd [88-91], Pt [92], and Rh [93-96], have been widely used either in bulk or in some supported form for the catalytic dechlorination (DC) of chlorinated hydrocarbons. Of all of the metals tested for this purpose, $\mathrm{Pd}$ is one of the most active and selective [97].

Various Pd-based BNMs have recently been used for the treatment of chlorinated hydrocarbons, where they exhibit high dechlorination efficiencies. For example, Pd-Fe bimetallic nanoparticles prepared by the chemical precipitation method in the liquid phase were found to be efficient for the DC of chlorinated methanes, and the optimal Pd loading and initial $\mathrm{pH}$ values were found to be $0.2 \mathrm{wt} \%$ and 7 , respectively [98]. The DC reaction complied with pseudo-first-order kinetics. Shih et al. [99] found that the DC of hexachlorobenzene (HCB) by Pd-Fe bimetallic particles proceeded at a faster rate than it did with Fe particles. By measuring different chlorinated intermediates and products, it has been possible to propose different pathways for the DC reactions of HCB by Fe and Pd-Fe particles. Bachas et al. [100] reported the preparation of a novel class of BNMs based on Pd-decorated Fe nanotubes for the DC of polychlorinated biphenyl (Scheme 10). The results showed a high DC efficiency, which was attributed to the high surface area to volume ratio of the hollow nanotubes structures.

Several other Pd-based BNMs have also been reported, including Pd-Ni, Pd-Al, and Pd-Ag. Lingaiah et al. [101] evaluated the activities of DC of chlorobenzene over a series of $\mathrm{Al}_{2} \mathrm{O}_{3}$ supported bimetallic Pd-Ni catalysts prepared by the deposition-precipitation method. Yu et al. [102] found that Pd-Al exhibited the highest stability towards 2-chlorobiphenyl of the various $\mathrm{Pd}-\mathrm{M}(\mathrm{M}=\mathrm{Mg}$, $\mathrm{Al}, \mathrm{Mn}, \mathrm{Zn}, \mathrm{Fe}, \mathrm{Sn}$, and $\mathrm{Cu}$ ) BNMs synthesized by aqueous cementation, as well as a relatively high reactivity.

Most recently, we reported the DC of 4-chlorophenol to phenol using narrowly distributed Ag-Pd nanocrystals with controllable compositions prepared using a one-pot synthesis [103]. The $\operatorname{AgPd}_{x} / \mathrm{C}(x=2,4,6,9,19)$ BNMs showed pronounced composition-dependent catalytic activities, leading to the $\mathrm{AgPd}_{9} / \mathrm{C}$ catalyst with excellent activity under mild conditions. This observation further prompted us to develop optimal bimetallic nanocatalysts with improved activities, and it was envisaged that a rational approach could be extended to other novel bimetallic nanocatalysts.

Using cheap metals instead of noble metals, it was possible to construct $\mathrm{M}-\mathrm{Fe}(\mathrm{M}=\mathrm{Pb}, \mathrm{Ni})$ catalysts that could also be successfully applied to the DC of chlorinated hydrocarbons

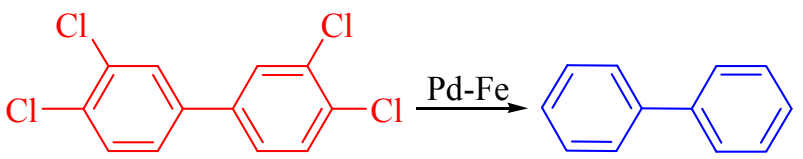

Scheme 10. Dechlorination of polychlorinated biphenyl catalyzed by Pd-decorated Fe nanotubes [100].
[104,105].

Other BNMs that have been reported for the DC reactions include $\mathrm{Au}-\mathrm{M}(\mathrm{M}=\mathrm{Ni}, \mathrm{Pt})$. For example, Keane et al. [106] compared the activity of the $\mathrm{Ni} / \mathrm{Al}_{2} \mathrm{O}_{3}$ and $\mathrm{Au} / \mathrm{Al}_{2} \mathrm{O}_{3}$ nanoparticles prepared by the impregnation method with that of $\mathrm{Au}-\mathrm{Ni} / \mathrm{Al}_{2} \mathrm{O}_{3}$ nanoparticles prepared by the reductive deposition of $\mathrm{Au}$ onto $\mathrm{Ni}$ in the catalytic gas-phase $\mathrm{DC}$ of 2,4-dichlorophenol. The $\mathrm{Au}-\mathrm{Ni} / \mathrm{Al}_{2} \mathrm{O}_{3}$ catalyst exhibited a lower $\mathrm{H}_{2}$ chemisorption capacity than the $\mathrm{Ni} / \mathrm{Al}_{2} \mathrm{O}_{3}$ catalyst, but both catalysts delivered equivalent initial activities. $\mathrm{Au} / \mathrm{Al}_{2} \mathrm{O}_{3}$ exhibited low $\mathrm{H}_{2}$ uptake and low activity to generate 2-chlorophenol as the sole product. In contrast, $\mathrm{Ni} / \mathrm{Al}_{2} \mathrm{O}_{3}$ exhibited an irreversible temporal deactivation where partial dechlorination to 2-chlorophenol was increasingly favored over the full dechlorination to phenol. The initial DC performance converged for both $\mathrm{Ni} / \mathrm{Al}_{2} \mathrm{O}_{3}$ and $\mathrm{Au}-\mathrm{Ni} / \mathrm{Al}_{2} \mathrm{O}_{3}$ but diverged with time onstream as $\mathrm{Ni} / \mathrm{Al}_{2} \mathrm{O}_{3}$ exhibited continual deactivation. In contrast, the combination of the reaction with thermal treatment elevated the DC performance of $\mathrm{Au}-\mathrm{Ni} / \mathrm{Al}_{2} \mathrm{O}_{3}$. Direct $\mathrm{HCl}$ treatment of the activated $\mathrm{Au}-\mathrm{Ni} / \mathrm{Al}_{2} \mathrm{O}_{3}$ could also lead to an increase in DC activity with the preferred full DC to phenol. This enhancement was attributed to the restructuring of the surface, leading to $\mathrm{Au}-\mathrm{Ni}$ clusters with a narrower (or more uniform) $\mathrm{Ni}$-Au composition. A surface $\mathrm{Ni}$-Au synergism was therefore proposed where the Au component serves to activate the $\mathrm{C}-\mathrm{Cl}$ bond(s) with subsequent attack from reactive hydrogen atoms dissociated at the Ni centers.

Kowalczyk et al. [107] recently prepared several $\mathrm{Al}_{2} \mathrm{O}_{3}-$ supported catalysts containing Pt using the impregnation method for the DC of tetrachloromethane. Differences were observed in the catalytic behavior of the Pt-rich and $\mathrm{Pt}-\mathrm{Au} / \mathrm{Al}_{2} \mathrm{O}_{3}$ catalysts $\left(\mathrm{Pt}_{100}, \mathrm{Pt}_{95} \mathrm{Au}_{5}\right.$, and $\left.\mathrm{Pt}_{90} \mathrm{Au}_{10}\right)$ with a similar metal particle size $(2.5-2.7 \mathrm{~nm})$ and were attributed to the alloying effect because a considerable degree of Pt-Au mixing was achieved in the bimetallic samples. It was found that the catalytic activity could be increased by introducing a very small amount of $\mathrm{Au}(\sim 10 \%)$ to the Pt, and that the moderate synergistic effect was related to a reduced tendency towards the chlorination of the surface when Pt is alloyed with $\mathrm{Au}$.

\subsubsection{Amidation}

In view of the importance of the development of powerful green catalysts and the common presence of amide bonds in natural products and synthetic compounds, Kobayashi et al. [108] studied amide bond forming reactions between alcohols and amines catalyzed by PI/CB Au-M (M = Fe, Co, Ni) nanoparticles using molecular oxygen as a terminal oxidant. A wide variety of alcohols $\mathbf{1 x}$ and amines $\mathbf{2 y}$, including aqueous ammonia and amino acids, could be used for this amide bond forming reaction using the optimized PI/CB Au-Co catalyst (Scheme 11). The catalyst could also be recovered and reused several times without any loss in activity.

\subsubsection{Reductive amination}

The direct synthesis of useful molecules from simple starting materials using one-pot tandem reactions is of particular importance in synthetic organic chemistry because of the in- 


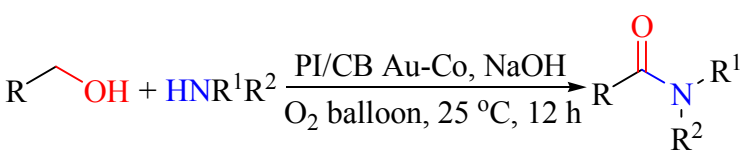

$$
\begin{aligned}
& \text { 1x 2y 3xy }
\end{aligned}
$$

Scheme 11. The synthesis of amides from alcohols and amines catalyzed by PI/CB Au-Co BNMs [108].

herent advantages associated with this approach. In this regard, metal nanoparticles (Pd, Pt) have been used to catalyze the direct one-pot reductive $\mathrm{C}-\mathrm{N}$ coupling reactions of carbonyl compounds with nitroarenes [109,110]. Most recently, we have successfully identified $\mathrm{Pd}_{1} \mathrm{Ag}_{1.7}$ as an optimal catalyst for the tandem reductive amination reactions between nitroarenes and aldehydes (Scheme 12) [111]. The optimum catalyst afforded a wide substrate scope and excellent recyclability as well as high activity and selectivity under ambient conditions. The key to the success of this catalyst was the ability to control the composition of the $\operatorname{Pd}_{1-x} \mathrm{Ag}_{x}(x=0-1)$ catalysts because a clear composition dependent activity/selectivity trend was observed in this study.

\subsubsection{Asymmetric 1,4-addition reactions of arylboronic acids to enones}

A robust and highly active PI/CB Rh-Ag catalyst for the asymmetric 1,4-addition of arylboronic acids to enones (Scheme 13) was recently developed by Kobayashi et al. [112]. The structures of the Rh-Ag catalysts and their chiral ligands have a significant impact on their catalytic activities and the amount of metal leaching. The catalyst could be recycled several times using simple procedures whilst still being able to provide high reaction yields and excellent enantioselectivities. To show the versatility of the PI/CB Rh-Ag catalyst, the one-pot oxidation-asymmetric 1,4-addition reaction of an allyl alcohol and an arylboronic acid was conducted by combining the PI/CB $\mathrm{Rh}-\mathrm{Ag}$ catalyst with PI/CB Au as an aerobic oxidation catalyst. The resulting catalytic system was not only useful in its own right as a synthetic methodology but could also provide new opportunities for heterogeneous, homogeneous, and metal nanocatalysis.

\subsubsection{Hydrogenolysis}

He et al. [113] reported the evaluation of the catalytic activities of several different $\mathrm{Ru}$ and $\mathrm{Ru}$-Re BMNs supported on $\mathrm{SiO}_{2}$, $\mathrm{ZrO}_{2}, \mathrm{TiO}_{2}, \mathrm{H}-\beta$, and $\mathrm{H}-\mathrm{ZSM} 5$ in the hydrogenolysis of glycerol to propanediols (i.e., 1,2-propanediol and 1,3-propanediol) at 160 ${ }^{\circ} \mathrm{C}$ and $8.0 \mathrm{MPa}$ over $8 \mathrm{~h}$. The Ru-Re catalysts showed much higher activity than the Ru catalysts with the Re having an obvious promoting effect on the performance of the catalysts. The coexistence of the Re and Ru components on these supports effectively changed the respective redox behavior of the individual materials on the supports, and therefore indicated the existence of a synergistic effect between the Ru and Re species on the bimetallic catalysts. To evaluate the influence of Re-Re on the reaction during the hydrogenolysis of glycerol, the hydrogenolysis reactions of some other products, including 1,2-propanediol, 1,3-propanediol, 1-propanol, and 2-propanol, were also examined over the $\mathrm{Ru}$ and $\mathrm{Ru}$-Re catalysts. The results demonstrated that glycerol preferred to be converted to 1,2-propanediol over the Ru-Re catalyst rather ethylene glycol, whereas 1,2-propanediol and 1,3-propanediol preferred to be converted to 1-propanol over the same catalyst.

Asakura et al. [114] prepared the carbon nanotube-supported $\mathrm{Ru}-\mathrm{Fe}(\mathrm{Ru}-\mathrm{Fe} / \mathrm{CNT})$ BNMs using a coimpregnation method for the selective hydrogenolysis of an aqueous $20 \%$ $(w / w)$ glycerol solution to produce glycols. The Ru-Fe/CNT possessed an average size similar to that of $\mathrm{Ru} / \mathrm{CNT}$ and was found to be more efficient for $\mathrm{C}-\mathrm{O}$ bond cleavage, where it afforded higher selectivity to glycols (i.e., 1,2-propanediol and ethylene glycol). Furthermore, the Ru-Fe/CNT catalyst was structurally robust and showed excellent reusability. XPS analysis indicated that some of the Fe species had interacted with the $\mathrm{Ru}$ moieties, forming $\mathrm{Ru}-\mathrm{Fe}$ alloys on the $\mathrm{Ru}$ domain, whereas other Fe species existed as iron oxides (most likely $\mathrm{FeO}$ and $\left.\mathrm{FeO}_{x}(1<x<1.5)\right)$ that were distributed predominantly on the periphery of the Ru-Fe BNMs. Although the presence of these iron oxide species was found to be critical to the stability of the Ru-Fe BNMs during the catalytic cycle, an excess of iron oxide species blocked the surfaces of the Ru-Fe nanoparticles, resulting in a decrease in the catalytic activity. The higher performance of the Ru-Fe/CNT catalyst was attributed to the synergistic effects resulting from the formation of Ru-Fe alloys

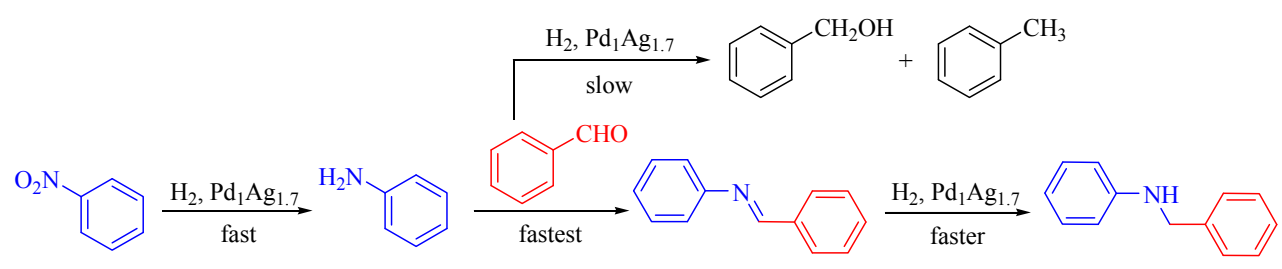

Scheme 12. Possible explanation of the observed selectivity of the reductive amination reaction [111].

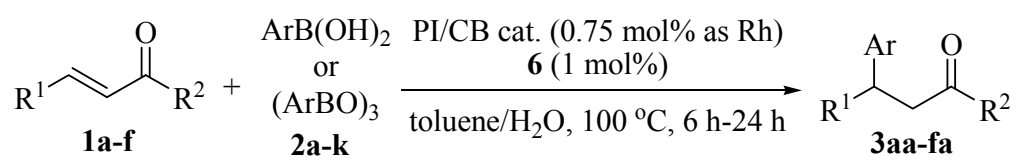

Scheme 13. Asymmetric 1,4-addition of arylboronic acids to enones [112].

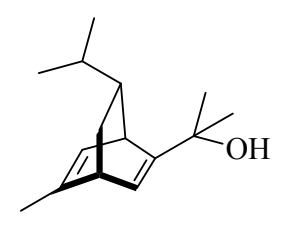

6 
and the interactions between the Ru-Fe nanoparticles and the iron oxides on the CNT surfaces.

\section{Summary and outlook}

Nanomaterials have emerged as green catalysts that offer new opportunities for the development of a sustainable chemical industry [115]. Although studies of bimetallic catalysts can be traced back to the early 1960s and research conducted at the Exxon Research and Engineering Company, the majority of the progress towards developing a better understanding of BNMs in terms of their roles in specific catalytic reactions has been made much more recently. This article provides an overview of some of the latest developments relating to BNM-catalyzed organic reactions, with particular emphasis on the selective oxidation of alcohols (e.g., benzylic alcohols), selective hydrogenation of various organic molecules (e.g., $\alpha, \beta$-unsaturated carbonyl compounds, simple alkenes, alkynes and substituted nitroarenes), and $\mathrm{C}-\mathrm{C}$ bond forming reactions. Despite the great success of BNMs in terms of their application to selective oxidation, hydrogenation, and coupling reactions, they have not yet found a wider application in tandem reactions for the synthesis of complex molecule [116-118]. Furthermore, reports pertaining to the use of BNMs in asymmetric organic synthesis are rather scarce, and significant scope therefore exists for developing a greater understanding of the fundamental properties and practical applications of these materials.

During the course of the last decade, the relationships between the catalytic properties (e.g., activity, selectivity, and durability) of BNMs and their structural characteristics in various reactions have been studied in great detail by many groups, and several key influencing factors have been identified, including surface structure, composition, size, and morphology. Unfortunately, some basic scientific issues have not yet been fully resolved [119]. For example, it is not yet possible to predict which BNMs would provide the best catalytic performance for a given chemical reaction or how and why adding a second metal has such a significant impact on the chemical properties of the particles. Furthermore, we do not currently know which structural feature are the most beneficial to the catalytic properties of the BNMs or the identities of the true active species during the catalytic reaction cycle. Indeed, it remains tremendously challenging to deliver satisfactory solutions to these problems.

Generally speaking, it is essential that a thorough understanding of the different types of mechanism available for bimetallic nanocatalysis is developed. One of these mechanisms is the nucleation and growth mechanism for the preparation of BNMs. Briefly, attention should be focused on understanding the underlying chemistry and identifying effective methods for achieving precise control over the formation process involved in the conversion of individual atoms to the BNM particles. The second of these mechanisms is the catalytic reaction mechanism. Reaction kinetics studies, theoretical modeling, catalyst surface characterization, and the validation of reaction intermediates would be beneficial for this particular mechanism to allow for the design of more effective catalysts, although these studies would ultimately require interdisciplinary collaborations. Notably, new analytical techniques and instrumentation for the in situ and operando studies are also required [120]. With the help of computational studies in catalysis, researchers would also be able to screen catalysts on a computer and design more effective catalysts [121].

To replace or even partially replace the traditional industrial noble-metal catalysts (i.e., $\mathrm{Pd} / \mathrm{C}$ and $\mathrm{Pt} / \mathrm{C}$ ), researchers are concentrating on developing a variety of promising BNMs through the rational design of novel nanostructures and the exploration of new catalytic reactions based on thermodynamic and kinetic studies of the different reaction processes. Although the practical application of BNMs in an industrial context is still some years away, the future development of bimetallic nanocatalysis may significantly benefit from the controllable synthesis of novel BNMs, as well as a deeper understanding of the mechanisms associated with these reactions and further progress towards computational studies of these catalysts.

\section{References}

[1] Yu W, Porosoff M D, Chen J G. Chem Rev, 2012, 112: 5780

[2] Cushing B L, Kolesnichenko V L, O'Connor C J. Chem Rev, 2004, 104: 3893

[3] Ferrando R, Jellinek J, Johnston R L. Chem Rev, 2008, 108: 845

[4] Wang D S, Li Y D. Adv Mater, 2011, 23: 1044

[5] Campbell C T. Annu Rev Phys Chem, 1990, 41: 775

[6] Gu J, Zhang Y-W, Tao F. Chem Soc Rev, 2012, 41: 8050

[7] Rodriguez J A. Surf Sci Rep, 1996, 24: 223

[8] Madey T E, Nien, C-H, Pelhos K, Kolodziej J J, Abdelrehim I M, Tao H-S. Surf Sci, 1999, 438: 191

[9] Schauermann S, Nilius N, Shaikhutdinov S, Freund H-J. Acc Chem Res, 2013, 46: 1673

[10] Zhou K B, Li Y D. Angew Chem Int Ed, 2012, 51: 602

[11] Pushkarev V V, Zhu Z, An K, Hervier A, Somorjai G A. Top Catal, 2012, 55: 1257

[12] Shi J L. Chem Rev, 2013, 113: 2139

[13] Sinfelt J H. Bimetallic Catalysts: Discoveries, Concepts, and Applications. New York: John Wiley \& Sons, 1983

[14] Roucoux A, Schulz J, Patin H. Chem Rev, 2002, 102: 3757

[15] Pyykko P. Angew Chem Int Ed, 2002, 41: 3573

[16] Wu W Q, Jiang H F. Acc Chem Res, 2012, 45: 1736

[17] Piera J, Bäckvall J-E. Angew Chem Int Ed, 2008, 47: 3506

[18] Punniyamurthy T, Velusamy S, Iqbal J. Chem Rev, 2005, 105: 2329

[19] Haruta M, Kobayashi T, Sano H, Yamada N. Chem Lett, 1987: 405

[20] Zhang Y, Cui X J, Shi F, Deng Y Q. Chem Rev, 2012, 112: 2467

[21] Mikami Y, Dhakshinamoorthy A, Alvaro M, García H. Catal Sci Technol, 2013, 3: 58

[22] Matsumoto T, Ueno M, Wang N, Kobayashi S. Chem Asian J, 2008, 3: 196

[23] Malat T, Baiker A. Chem Rev, 2004, 104: 3037

[24] Della Pina C, Falletta E, Rossi M. J Catal, 2008, 260: 384

[25] Huang X M, Wang X G, Wang X S, Wang X X, Tan M W, Ding W Z, Lu X G. J Catal, 2013, 301: 217

[26] Huang X M, Wang X G, Tan M W, Zou X J, Ding W Z, Lu X G. Appl Catal A, 2013, 467: 407

[27] Li W J, Wang A Q, Liu X Y, Zhang T. Appl Catal A, 2012, 433-434: 146

[28] Sugano Y, Shiraishi Y, Tsukamoto D, Ichikawa S, Tanaka S, Hirai T. Angew Chem Int Ed, 2013, 52: 5295 
[29] Chen Y T, Lim H M, Tang Q H, Gao Y T, Sun T, Yan Q Y, Yang Y H. Appl Catal A, 2010, 380: 55

[30] Balcha T, Strobl J R, Fowler C, Dash P, Scott R W J. ACS Catal, 2011, 1: 425

[31] Miyamura H, Matsubara R, Kobayashi S. Chem Commun, 2008: 2031

[32] Dimitratos N, Villa A, Wang D, Porta F, Su D S, Prati L. J Catal, 2006, 244: 113

[33] Villa A, Janjic N, Spontoni P, Wang D, Su D S, Prati L. Appl Catal A, 2009, 364: 221

[34] Enache D I, Edwards J K, Landon P, Solsona-Espriu B, Carley A F, Herzing A A, Watanabe M, Kiely C J, Knight D W, Hutchings G J. Science, 2006, 311: 362

[35] Kaizuka K, Miyamura H, Kobayashi S. J Am Chem Soc, 2010, 132: 15096

[36] Yoo W J, Miyamura H, Kobayashi S. J Am Chem Soc, 2011, 133: 3095

[37] Kesavan L, Tiruvalam R, Ab Rahim M H, bin Saiman M I, Enache D I, Jenkins R L, Dimitratos N, Lopez-Sanchez J A, Taylor S H, Knight D W, Kiely C J, Hutchings G J. Science, 2011, 331: 195

[38] bin Saiman M I, Brett G L, Tiruvalam R, Forde M M, Sharples K, Thetford A, Jenkins R L, Dimitratos N, Lopez-Sanchez J A, Murphy D M, Bethell D, Willock D J, Taylor S H, Knight D W, Kiely C J, Hutchings G J. Angew Chem Int Ed, 2012, 51: 5981

[39] Alonso F, Riente P, Yus M. Acc Chem Res, 2011, 44: 379

[40] Yan N, Zhao C, Luo C, Dyson P J, Liu H C, Kou Y. J Am Chem Soc, 2006, 128: 8714

[41] Xu K L, Zhang Y, Chen X R, Huang L, Zhang R, Huang J. Adv Synth Catal, 2011, 353: 1260

[42] Corma A, Serna P, Concepción P, Calvino J J. J Am Chem Soc, 2008, 130: 8748

[43] Tsang S C, Cailuo N, Oduro W, Kong A T S, Clifton L, Yu K M K, Thiebaut B, Cookson J, Bishop P. ACS Nano, 2008, 2: 2547

[44] Zheng R Y, Porosoff M D, Weiner J L, Lu S L, Zhu Y X, Chen J G. Appl Catal A, 2012, 419-420: 126

[45] Gual A, Godard C, Castillón S, Claver C. Dalton Trans, 2010, 39: 11499

[46] Blaser H-U, Steiner H, Studer M. ChemCatChem, 2009, 1: 210

[47] Wei H-H, Yen C H, Lin H-W, Tan C-S. J Supercrit Fluid, 2013, 81: 1

[48] Wu Y E, Cai S F, Wang D S, He W, Li Y D. J Am Chem Soc, 2012, 134: 8975

[49] Wang D S, Li Y D. J Am Chem Soc, 2010, 132: 6280

[50] Duan H H, Wang D S, Kou Y, Li Y D. Chem Commun, 2013, 49: 303

[51] Lonergan W W, Vlachos D G, Chen J G. J Catal, 2010, 271: 239

[52] Studt F, Abild-Pedersen F, Bligaard T, Sørensen R Z, Christensen C H, Nørskov J K. Science, 2008, 320: 1320

[53] Vang R T, Honkala K, Dahl S, Vestergaard E K, Schnadt J, Lægsgaard E, Clausen B S, Nørskov J K, Besenbacher F. Nat Mater, 2005, 4: 160

[54] Wehrli J T, Thomas D J, Wainwright M S, Trimm D L, Cant N W. Appl Catal, 1990, 66: 199

[55] Wehrli J T, Thomas D J, Wainwright M S, Trimm D L, Cant N W. Appl Catal, 1991, 70: 253

[56] Menezes W G, Altmann L, Zielasek V, Thiel K, Bäumer M. J Catal, 2013, 300: 125

[57] Nakamula I, Yamanoi Y, Imaoka T, Yamamoto K, Nishihara H. Angew Chem Int Ed, 2011, 50: 5830

[58] Cai S F, Duan H H, Rong H P, Wang D S, Li L S, He W, Li Y D. ACS Catal, 2013, 3: 608

[59] Xia B H, He F, Li L D. Langmuir, 2013, 29: 4901

[60] Jiang H-L, Akita T, Ishida T, Haruta M, Xu Q. J Am Chem Soc, 2011, 133: 1304
[61] Cardenas-Lizana F, Gomez-Quero S, Hugon A, Delannoy L, Louis C, Keane M A. J Catal, 2009, 262: 235

[62] Corbos E C, Ellis, P R, Cookson J, Briois V, Hyde T I, Sankar G, Bishop P T. Catal Sci Technol, 2013, DOI: 10.1039/c3cy00255a

[63] Liu M H, Bai Q, Xiao H L, Liu Y Y, Zhao J, Yu W W. Chem Eng J, 2013, 232: 89

[64] Xie Y L, Xiao N, Ling Z, Liu Y, Yu C, Qiu J S. Chin J Catal (解雅玲, 肖 南, 凌铮, 柳月, 于畅, 邱介山. 催化学报), 2012, 33: 1883

[65] Müslehiddinoğlu J, Li J, Tummala S, Deshpande R. Org Process Res Dev, 2010, 14: 890

[66] Johansson Seechurn C C C, Kitching M O, Colacot T J, Snieckus V. Angew Chem Int Ed, 2012, 51: 5062

[67] Hyotanishi M, Isomura Y, Yamamoto H, Kawasaki H, Obora Y. Chem Commun, 2011, 47: 5750

[68] Li C C, Sato R, Kanehara M, Zeng H B, Bando Y, Teranishi T. Angew Chem Int Ed, 2009, 48: 1

[69] Zhang R Z, Liu J M, Li F W, Wang S F, Xia C G, Sun W. Chin J Chem, 2011, 29: 525

[70] Shen Y-M, Du Y-J, Zeng M-F, Zhi D, Zhao S-X, Rong L-M, Lv S-Q, Du L, Qi C-Z. Appl Organomet Chem, 2010, 24: 631

[71] Wu Y E, Wang D S, Zhao P, Niu Z Q, Peng Q, Li Y D. Inorg Chem, 2011, 50: 2046

[72] Tan L F, Wu X L, Chen D, Liu H Y, Meng X W, Tang F Q. J Mater Chem A, 2013, 1: 10382

[73] Shaabani A, Mahyari M. J Mater Chem A, 2013, 1: 9303

[74] Alonso A, Shafir A, Macanás J, Vallribera A, Muñoz M, Muraviev D N. Catal Today, 2012, 193: 200

[75] Kim S-J, Oh S-D, Lee S, Choi S-H.J Ind Eng Chem, 2008, 14: 449

[76] Xu W, Sun Y L, Guo M H, Zhang W Q, Gao Z W. Chin J Org Chem (徐 伟, 孙原龙, 郭萌涵, 张伟强, 高子伟. 有机化学), 2013, 33: 820

[77] Durand J, Teuma E, Gomez M. Eur J Inorg Chem, 2008: 3577

[78] Phan N T S, Van Der Sluys M, Jones C W. Adv Synth Catal, 2006, 348: 609

[79] Widegren J A, Finke R G. J Mol Catal A, 2003, 198: 317

[80] Fang P-P, Jutand A, Tian Z-Q Amatore C. Angew Chem Int Ed, 2011, 50: 12184

[81] Karam A, Alonso J C, Gerganova T I, Ferreira P, Bion N, Barrault J, Jerome F. Chem Commun, 2009: 7000

[82] Dhital R N, Kamonsatikul C, Somsook E, Sakurai H. Catal Sci Technol, 2013, DOI: 10.1039/c3cy00303e

[83] Niu Z Q, Peng Q Zhuang Z B, He W, Li Y D. Chem Eur J, 2012, 18: 9813

[84] Ordóñez S, Sastre H, Diez F V. React Kinet Catal Lett, 2000, 70: 61

[85] Shin E J, Keane M A. J Catal, 1998, 173: 450

[86] Feng J T, Lin Y J, Evans D G, Duan X, Li D-Q. J Catal, 2009, 266: 351

[87] Wu W H, Xu J, Ohnishi R. Appl Catal B, 2005, 60: 129

[88] Meshesha B T, Chimentao R J, Segarra A M, Llorca J, Medina F, Coq B, Sueiras J E. Appl Catal B, 2011, 105: 361

[89] Díaz E, Faba L, Ordóñez S. Appl Catal B, 2011, 104: 415

[90] Díaz E, Ordóñez S, Bueres R F, Asedegbega-Nieto E, Sastre H. Appl Catal B, 2010, 99: 181

[91] Janiak T, Okal J. Appl Catal B, 2009, 92: 384

[92] Bonarowska M, Kaszkur Z, Kępiński L, Karpiński Z. Appl Catal B, 2010, 99: 248

[93] Coq B, Ferrat G, Figueras F. J Catal, 1986, 101: 434

[94] Ordóñez S, Sastre H, Díez F V. Appl Catal B, 2003, 40: 119

[95] Amenomiya Y, Birss V I, Goledzinowski M, Galuszka J, Singer A R. Catal Rev-Sci Eng, 1990, 32: 163

[96] Diaz E, Mohedano A F, Casas J A, Calvo L, Gilarranz M A, Rodriguez JJ. Appl Catal B, 2011, 106: 469

[97] Bertolini J C, Jugnet Y. In: Woodruff D P Ed. Surfaces Alloy and Alloys Surface. Amsterdam: Elsevier, 2002.404 


\title{
Graphical Abstract
}

Chin. J. Catal., 2013, 34: 1964-1974 doi: 10.1016/S1872-2067(12)60701-3

\section{Progress in organic reactions catalyzed by bimetallic nanomaterials}

Shuangfei Cai, Dingsheng Wang, Zhiqiang Niu, Yadong Li*

Tsinghua University; National Center for Nanoscience and Technology

The interest in the bimetallic nanocatalysis is increasing dramatically. This review focuses on the progress in the organic reactions catalyzed by bimetallic nanomaterials.

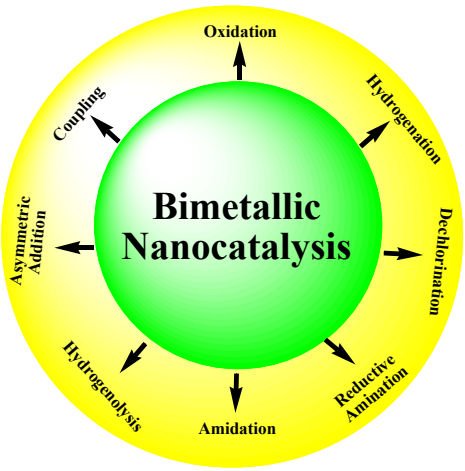

[98] Wang X Y, Chen C, Chang Y, Liu H L. J Hazard Mater, 2009, 161: 815

[99] Shih Y H, Chen Y C, Chen M Y, Tai Y T, Tso C P. Colloids Surf A, 2009, 332: 84

[100]Zahran E M, Bhattacharyya D, Bachas L G. Chemosphere, 2013, 91 : 165

[101]Babu N S, Lingaiah N, Sai Prasad P S. Appl Catal B, 2012, 111-112: 309

[102]Yang B, Deng S B, Yu G, Zhang H, Wu J H, Zhuo Q F. J Hazard Mater, 2011, 189: 76

[103] Rong H P, Cai S F, Niu Z Q, Li Y D. ACS Catal, 2013, 3: 1560

[104] Nie X Q Liu J G, Yue D B, Zeng X W, Nie Y F. Chemosphere, 2013, 90 2403

[105] Parshetti G K, Doong R A. Chemosphere, 2012, 86: 392

[106] Keane M A, Gómez-Quero S, Cárdenas-Lizana F, Shen W Q. ChemCatChem, 2009, 1: 270

[107]Legawiec-Jarzyna M, Juszczyk W, Bonarowska M, Kaszkur Z, Kępiński L, Kowalczyk Z, Karpiński Z. Top Catal, 2009, 52: 1037

[108] Soulé J-F, Miyamura H, Kobayashi S. J Am Chem Soc, 2011, 133: 18550
[109] Hu L, Cao X Q, Ge D H, Hong H Y, Guo Z Q, Chen L, Sun X H, Tang J X, Zheng J W, Lu J M, Gu H W. Chem Eur J, 2011, 17: 14283

[110] Sreedhar B, Reddy P S, Devi D K. J Org Chem, 2009, 74: 8806

[111] Li L S, Niu Z Q, Cai S F, Zhi Y, Li H, Rong H P, Liu L C, Liu L, He W, Li Y D. Chem Commun, 2013, 49: 6843

[112] Yasukawa T, Miyamura H, Kobayashi S. J Am Chem Soc, 2012, 134: 16963

[113] Ma L, He D H. Top Catal, 2009, 52: 834

[114] Li B D, Wang J, Yuan Y Z, Ariga H, Takakusagi S, Asakura K. ACS Catal, 2011, 1: 1521

[115] Astruc D. Nanoparticles and Catalysis. Weinheim: Wiley-VCH Verlag GmbH \& Co. KGaA, 2008. 2

[116] Patil N T. ChemCatChem, 2011, 3: 1121

[117] Myers V S, Weir M G, Carino E V, Yancey D F, Pande S, Crooks R M. Chem Sci, 2011, 2: 1632

[118] Cong H, Porco J A Jr. ACS Catal, 2012, 2: 65

[119] Liu X W, Wang D S, Li Y D. Nano Today, 2012, 7: 448

[120] Tao F. Chem Soc Rev, 2012, 41: 7977

[121]Tao F, Zhang S, Nguyen L, Zhang X Q. Chem Soc Rev, 2012, 41: 7980

\section{双金属纳米材料催化的有机反应进展}

\author{
蔡双飞 ${ }^{\mathrm{a}, \mathrm{b}}$, 王定胜 ${ }^{\mathrm{a}}$, 牛志强 ${ }^{\mathrm{a}}$, 李亚栋, ${ }^{\mathrm{a}}$,

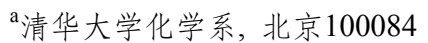 \\ b国家纳米科学中心，北京 100190
}

\begin{abstract}
摘要: 纳米催化介于均相催化与多相催化之间, 也称为”半多相催化”, 目前正受到人们越来越多的关注. 最近几年, 应用双金属纳 米材料进行催化研究取得了很大进展, 使用这些催化材料可以增加反应活性和选择性, 而且能很好地得以回收. 本文综述了双金 属纳米材料催化的各种有机反应, 如选择性氧化/氢化、偶联和其它反应(脱卤、酰胺化、还原氨化、芳基嗍酸与烯酮的1,4-不对 称加成和氢解). 将双金属纳米材料用于催化合成更加复杂的有机分子值得期待. 在双金属纳米有机催化领域, 基础理论和实际 应用尚有较大的发展空间. 未来该领域的发展需要开展多学科的合作，包括合理设计和可控制备相关的双金属纳米材料、深入理 解催化机理及发展计算催化.
\end{abstract}

关键词：双金属纳米合金; 催化剂; 有机反应; 多相催化

收稿日期: 2013-07-20. 接受日期: 2013-09-02. 出版日期: 2013-11-20.

*通讯联系人. 电话: (010)62772350; 传真: (010)62788765; 电子信箱: ydli@mail.tsinghua.edu.cn

基金来源：国家纳米科技基础研究重大项目(2011CB932401，2011CBA00500，2012CB224802); 国家自然科学基金(21221062, 21131004, 21322107, 21171105).

本文的英文电子版由Elsevier出版社在ScienceDirect上出版(http://www.sciencedirect.com/science/journal/18722067). 